\title{
Evidence of rapid transfer and bioaccumulation of Microcystin-LR poses potential risk to freshwater prawn Macrobrachium rosenbergii (de Man)
}

\author{
Li-Ping Liu ${ }^{1}$, Xiao-Ming Su${ }^{1}$, Tao-Ying Chen ${ }^{1}$, Kang Li ${ }^{1}$, Jia Zhan ${ }^{2}$, Hillary Egna ${ }^{3}$ \& James Diana ${ }^{4}$ \\ ${ }^{1}$ Key Laboratory of Exploration and Utilization of Aquatic Genetic Resources, Shanghai Ocean University, Ministry of \\ Education, Shanghai, China \\ ${ }^{2}$ Ningbo Entry-exit Inspection and Quarantine Bureau of P.R. China, Ningbo, China \\ ${ }^{3}$ AquaFish Innovation Lab, Oregon State University, Corvallis, OR, USA \\ ${ }^{4}$ School of Natural Resources and Environment, University of Michigan, Ann Arbor, MI, USA
}

Correspondence: L-P Liu, College of Fisheries and Life Science, Shanghai Ocean University, 999 Huchenghuan Road, Shanghai 201306, China. E-mail: lp-liu@shou.edu.cn

\begin{abstract}
Microcystins accumulate in aquatic organisms and can be transferred to higher trophic levels, eventually affecting vector animals and consumers. We examined three levels of an aquatic food chain (Microcystis aeruginosa, Daphnia magna and Macrobrachium rosenbergii) to identify the transfer efficiency and risk of microcystin on prawns. Samples were analysed using ultra performance liquid chromatography-mass spectrometry (MS)/MS and microcystin-LR (MC-LR) distributions in prawn tissues were studied. The results showed that prawns accumulate MC-LR both directly from M. aeruginosa and indirectly through D. magna which was pre-exposed to M. aeruginosa. MC-LR was detected in the gills, digestive tracts and hepatopancreas of the prawns $2 \mathrm{~h}$ after exposure. MC-LR accumulated in prawns to $0.49 \pm 0.04 \mu \mathrm{g} \mathrm{g}^{-1}$ dry weight in hepatopancreas within $24 \mathrm{~h}$, while it was not detected in muscle samples, and rarely appeared in blood samples in such a short period. Although MC-LR was not detected in muscle, the head including hepatopancreas of the prawns accumulated troublesome amounts of MC-LR. These results demonstrate that microcystis blooms in prawn farming potentially pose a risk to human consumers, although prawns may be exposed to the bloom for a very short time, hence regular monitoring of blue green algae population is recommended.
\end{abstract}

Keywords: Macrobrachium rosenbergii, Microcystin-LR, bioaccumulation, food safety

\section{Introduction}

Toxic cyanobacterial blooms are globally problematic as they may produce secondary metabolites such as microcystins (MC) (Vareli, Zarali, Zacharioudakis, Vagenas, Varelis, Pilidis, Briasoulis \& Sainis 2012; Beaver, Manis, Loftin, Graham, Pollard \& Mitchell 2014). So far, more than 80 variants have been isolated and identified (Dietrich \& Hoeger 2005). Among these isoforms, Microcystin-LR (MC-LR) is the most common and most toxic to mammals. Studies have demonstrated that MCs can cause toxic effect on various aquatic organisms (Cazenave, Wunderlin, Bistoni, Améd, Krause, Pflugmacher \& Wiegand 2005; Chen \& Xie 2005; Xie, Xie, Guo, Li, Miyabara \& Park 2005; Lance, Brient, Bormans \& Gérard 2006; Xie, Yokoyama, Nakamura \& Park 2007; Deblois, Aranda-Rodriguez, Giani \& Bird 2008; Ortiz-Rodríguez \& Wiegand 2010; Deblois, Gianib \& Bird 2011; Liu, Li, Chen, Dai, Jiang \& Diana 2011; Ziková, Lorenz, Lutz, Pflugmacher \& Kloas 2013; Liu, Qiao, Chen, Wu \& Zhang 2014). Aquaculture species are exposed to MC through the aquatic food web (Andersen, Luu, Chen, Holmes, Kent, Le Blanc, Taylor \& Williams 1993; Ibelings, Bruning, de Jonge, Wolfstein, Pires, Postma \& Burger 2005; Smith \& Haney 2006). Trophic transfer has also 
been demonstrated under laboratory conditions in which hepatotoxins were transferred from zooplankton to fish (Engström-Öst, Lehtiniemi, Green, Kozlowsky-Suzuki \& Viitasalo 2002; Karjalainen, Reinikainen, Spoof, Meriluoto \& Sivonen 2005; Smith \& Haney 2006).

Microcystin-LR also poses potential threats to human health (Codd, Lindsay, Young, Morrison \& Metcalf 2005; Codd, Morrison \& Metcalf 2005; Ibelings \& Chorus 2007). The transfer of MC to higher trophic levels through the food web poses serious health implications (Ozawa, Yokoyama, Ishikawa, Kumagai, Watanabe \& Park 2003). Recently, MC were identified for the first time in the serum (average $0.228 \mathrm{ng} \mathrm{mL}^{-1}$ ) of fishermen who were chronically exposed to cyanotoxins in Lake Chaohu, China, indicating hepatocellular damage (Chen, Xie, Li \& Xu 2009; Chen, Zhang, Xie, Wang \& Ma 2009). An important exposure route for humans is through the ingestion of contaminated aquatic food. The World Health Organization (WHO) published a guideline of $1 \mu \mathrm{g} \mathrm{kg}^{-1}$ of MC in drinking water, and established a tolerable daily intake guideline (TDI) of $0.04 \mu \mathrm{g} \mathrm{kg}^{-1} \mathrm{day}^{-1}$ (Chorus \& Bartram 1999).

In recent years, studies evaluating MC contamination in aquatic organisms from natural waters with cyanobacterial blooms have increased, but these studies mainly focused on fish (Mohamed, Carmichael \& Hussein 2003; Ibelings et al. 2005; Xie et al. 2005; Chen, Xie, Zhang, Ke \& Yang 2006; Deblois et al. 2008; Wilson, Gossiaux, Hook, Berry, Landrum, Dyble \& Guildford 2008). Similar information is relatively rare for freshwater prawns. Freshwater prawns are commercially important, because they are used for human consumption worldwide. In both intensive and extensive aquaculture, phytoplankton succession mimics natural systems, with cyanobacterial abundance reaching its maximum in summer (Smith, Boyer \& Zimba 2008).

Zooplankton can accumulate MC and therefore may act as vectors of the toxin up the aquatic food web; however, information on the transfer and bioaccumulation efficiency of MC through prawns is lacking. It is likely that consumption of prawns exposed to high MC levels could lead to risk of public health. Quantitative evaluation of the potential risk posed to food safety is needed. Therefore, we monitored transfer and bioaccumulation of MC-LR at three levels of an aquatic food chain, namely blue green alga Microcystis aeruginosa, daphnia Daphnia magna and freshwater prawns Macrobrachium rosenbergii in three experiments so as to assess its potential risk by human consumption of prawns.

\section{Materials and methods}

\section{Chemicals and reagents}

Microcystin-LR (purity $\geq 95.0 \%$ ) was purchased from Alexis (Lausen, Switzerland). Standard stock solution was prepared in methanol at $0.50 \mu \mathrm{g} \mathrm{mL}^{-1}$. High performance liquid chromatography (HPLC)-grade methanol and formic acid were supplied by Merck KGaA (Darmstadt, Germany). All other reagents and chemicals used were of analytical grade. Water was purified from a Milli$\mathrm{Q}$ deionization unit (Millipore, Molsheim, France).

Microcystis aeruginosa was cultured in BG-11 medium in flasks at $25 \pm 1^{\circ} \mathrm{C}$, with irradiance at $56 \mu \mathrm{Em}^{-2} \mathrm{~s}^{-1}$ and a $12 \mathrm{~h}$ light: $12 \mathrm{~h}$ dark photoperiod. D. magna was provided by Key Laboratory of Marine Ecology and Environmental Science, Institute of Oceanology, Academy of Science (Qingdao City, China).

\section{Experimental design}

Experiment A was an exposure experiment where prawns and D. magna were exposed to M. aeruginosa water. Prawns with an average weight of $12.92 \pm 2.79 \mathrm{~g}$ and body length of $8.36 \pm 0.57 \mathrm{~cm}$ were obtained from a local farm (Shanghai, China), acclimated for 1 week in PVC tanks (150 L) containing de-chlorinated water and fed with commercial prawn feed (Tongwei Group, Chengdu, China) at a rate of $3 \%$ of body weight per day. The water temperature was $25 \pm 1^{\circ} \mathrm{C}$, and dissolved oxygen was $5.9 \pm 0.6 \mathrm{mg} \mathrm{L}^{-1}$. Fresh cells of $M$. aeruginosa were used for this experiment, after being concentrated by centrifugation $\left(4 \mathrm{~min}, 5400 \mathrm{~g}, 4^{\circ} \mathrm{C}\right.$ ) and resuspended in water at cell densities of $5 \times 10^{7}$ cells $\mathrm{mL}^{-1}$. D. magna at density of 2 individual $\mathrm{mL}^{-1}$ was maintained in five glass tanks each with $10 \mathrm{~L}$ in volume containing water with $M$. aeruginosa at density of $5 \times 10^{7}$ cells $\mathrm{mL}^{-1}$ for $24 \mathrm{~h}$. Each group of prawns ( 4 groups, $n=10$ ) was placed in a $30 \mathrm{~L} \mathrm{PVC} \mathrm{tanks} \mathrm{containing} \mathrm{water} \mathrm{with} \mathrm{M.} \mathrm{aeru-}$ ginosa at the density of $5 \times 10^{7}$ cells $\mathrm{mL}^{-1}$ for 24 h. During exposure the prawns were fed with commercial feed and aeration was provided. 
Prawns were sampled from tanks and dissected at 2, 8, 16 and $24 \mathrm{~h}$ of exposure. The gills, blood, digestive tract, muscle and hepatopancreas were frozen and freeze-dried separately. D. magna was collected and frozen for MC-LR content analysis and feeding experiment $\mathrm{B}$.

Experiment B was a feeding experiment, where prawns were fed with D. magna which was exposed to $M$. aeruginosa in experiment A. The prawns (average weight of $13.87 \pm 2.52 \mathrm{~g}$ and body length of $8.65 \pm 0.47 \mathrm{~cm}$ ) were acclimated to laboratory conditions for 1 week in PVC tanks with de-chlorinated water. During acclimation period commercial feed was supplied, while when the experiment began prawns were exclusively fed with frozen D. magna exposed to M. aeruginosa. Prawns were sampled and dissected at 8, 16 and $24 \mathrm{~h}$ post feeding and the gills, blood, digestive tract, muscle and hepatopancreas were frozen and freeze-dried separately.

Experiment $\mathrm{C}$ was a food chain experiment where prawns (average weight of $13.25 \pm 2.85 \mathrm{~g}$ and body length of $8.43 \pm 0.86 \mathrm{~cm}$ ) were acclimated to laboratory conditions for 1 week in five PVC tanks. Prawns along with D. magna (two individuals $\mathrm{mL}^{-1}$ ) were stocked in $30 \mathrm{~L}$ PVC tanks with M. aeruginosa at cell densities of $5 \times 10^{7}$ cells $\mathrm{mL}^{-1}$. Prawns from each tank were dissected at 2, 8, 16 and $24 \mathrm{~h}$ and the gills, blood, digestive tract, muscle and hepatopancreas were frozen and freeze-dried separately.

\section{MC analyses}

Extraction of the MC was carried out according to the method of Zhang, Xie, Chen, Dai, Qiu, Liu and Liang (2009) with some modification. The lyophilized samples ( $\sim 0.1 \mathrm{~g}$ dry weight for each sample) were extracted two times with $25 \mathrm{~mL}$ of $0.01 \mathrm{M}$ Ethylene diamine tetraacetic acid (EDTA) $-\mathrm{Na}_{2}-5 \mathrm{v} /$ $\mathrm{v} \%$ formic acid by homogenization with a highspeed blender (PT2000; Polytron, Luzern, Switzerland) for $30 \mathrm{~s}$ at $15000 \mathrm{~g}$ and followed by 5-min sonication. The samples were then centrifuged at $3000 \mathrm{~g}$ (Type 3K-18; Sigma, Germany) at $4^{\circ} \mathrm{C}$. The supernatant was applied to an Oasis HLB cartridge (500 mg, $6 \mathrm{~mL}$; Waters, Milford, MA, USA) which had been preconditioned by washing with $5 \mathrm{~mL} \mathrm{100 \%} \mathrm{methanol} \mathrm{and} 10 \mathrm{~mL}$ distilled water. The column containing sample was washed with $5 \mathrm{~mL}$ water followed by $3 \mathrm{~mL} \mathrm{10 \%} \mathrm{methanol,} \mathrm{and}$ then eluted with $4 \mathrm{~mL} 100 \%$ methanol. The elut- riant was dried under a nitrogen stream in a $45^{\circ} \mathrm{C}$ water bath, and the residue was dissolved in $1.5 \mathrm{~mL}$ of $20 \%$ methanol with $0.1 \%$ formic acid. The resulting solution was filtered through a $0.45 \mu \mathrm{m}$ nylon filter for analysis.

An ultra performance liquid chromatography (UPLC) and mass spectrometry system was used consisting of an Acquity UPLC ${ }^{\mathrm{TM}}$ system equipped with a XEVO triple quadrupole mass spectrometer (Waters). The injection volume was full-loop $(10 \mu \mathrm{L})$ and the chromatographic separation was performed at $40^{\circ} \mathrm{C}$ using a $\mathrm{C}_{18}$ column (Waters, $100 \mathrm{~mm} \times 2.1 \mathrm{~mm}$ internal diameter, $1.8 \mu \mathrm{m}$ particle size), with the flow rate set at $0.35 \mathrm{~mL} \mathrm{~min}^{-1}$. The mass spectrometer was operated in the positive electrospray ionization (ESI) mode, with a capillary voltage of $3.5 \mathrm{kV}$. The source and desolvation temperatures were 145 and $450^{\circ} \mathrm{C}$ respectively. Gas desolvation and nebulization were carried out using nitrogen at flow rates of 850 and $50 \mathrm{~L} \mathrm{~h}^{-1}$ respectively. The signal acquisition was performed by multiple reactions monitoring mode. The divert valve was programmed to send the liquid chromatography (LC) flow to waste for the first 2 min after injection and again after the analyte of interest had eluted. The gradient parameters are presented in Table 1. Mass spectrum tuning and optimization were achieved by infusing MC-LR and monitoring the $[\mathrm{M}+\mathrm{H}]^{+}$ion at $\mathrm{m} / \mathrm{z}$ 995.6. The product ions at $\mathrm{m} / \mathrm{z} 107.1$ from the parent ion at $m / z$ 995.6 were used for MC-LR qualitative analysis. For quantification purposes, mass chromatograms monitored the product ions at $\mathrm{m} / \mathrm{z}$ 135.2 from the parent ion at $\mathrm{m} / \mathrm{z} 995.6$ (Table 2).

The method was validated in terms of specificity, limit of detection (LOD), limit of quantification (LOQ), precision and recovery. Linearity of the method was assessed at MC-LR concentration

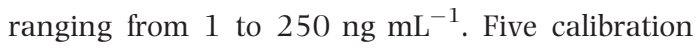
curves with six concentration points were constructed. The linearity of the calibration curves

Table 1 UPLC gradient parameters

\begin{tabular}{lrrl}
\hline Time (min) & A $^{*}$ & B十 & Curve \\
\hline 0.00 & 100 & 0 & 0 \\
5.00 & 0 & 100 & 6 \\
6.00 & 0 & 100 & 6 \\
6.10 & 100 & 0 & 1 \\
7.60 & 100 & 0 & 1 \\
\hline
\end{tabular}

*Water containing $0.1 \%(\mathrm{v} / \mathrm{v})$ formic acid.

$\dagger$ Methanol containing $0.1 \%(\mathrm{v} / \mathrm{v})$ formic acid. 
Table 2 UPLC-MS/MS acquisition parameter for MC-LR analysis

\begin{tabular}{llll}
\hline Parent ion/Product ion & $\begin{array}{l}\text { Cone } \\
\text { voltage(v) }\end{array}$ & $\begin{array}{l}\text { Collision } \\
\text { energy(v) }\end{array}$ & $\begin{array}{l}\text { Dwell } \\
\text { time(s) }\end{array}$ \\
\hline $995.6 / 107.1^{*}$ & 42 & 70 & 0.2 \\
$995.6 / 135.2$ & 42 & 76 & 0.2 \\
\hline
\end{tabular}

*Quantification transition.

was evaluated on the basis of linear regression analysis and the square correlation coefficients $\left(r^{2}\right)$ using sPss 17.0 (IBM Corporation, Armonk, NY, USA). A correlation coefficient above 0.99 was desirable for all the calibration curves. LOD and LOQ were defined as concentrations in a sample resulting in signal-to-noise ratios of 3 and 10 respectively. Precision of the assay was expressed by per cent relative standard deviation (\% RSD).

The recoveries were obtained by analysing MC-LR in prawn tissue at three spiked concentration $\left(0.075,1.5,3.75 \mu \mathrm{g} \mathrm{g}^{-1}\right.$ for MC-LR). In all cases, samples were run in sextuplicate. The LOD and LOQ were estimated sextuplicate. The matrix effect was assessed by comparing the peak areas of the neat analyte standards, standards spiked before and after extraction in prawn tissue samples. Mean and standard deviation of MC concentrations between treatments were performed using SPss 17.0 for windows.

\section{Results}

\section{MC analyses}

One possible way to remove the matrix interferences from prawn tissue is sample cleanup using an Oasis HLB extraction cartridge (Waters). There are many interfering compositions unclear in complex prawn tissue, which ideally should be washed off before elution. We successfully used $3 \mathrm{~mL}$ of $10 \%$ methanol in water to wash off the interference of the matrix while leaving the targeted compounds on the cartridge. The washing curve is shown in Fig. 1. Pure methanol was chosen for elution, because of its high recovery and convenient dryness by nitrogen flush. The volume fraction of pure methanol in water was $4 \mathrm{~mL}$ and the elution curve is shown in Fig. 2.

According to the analysis of 10 unexposed samples (including gills, blood, digestive tract, muscle and hepatopancreas), this UPLC-MS/MS method

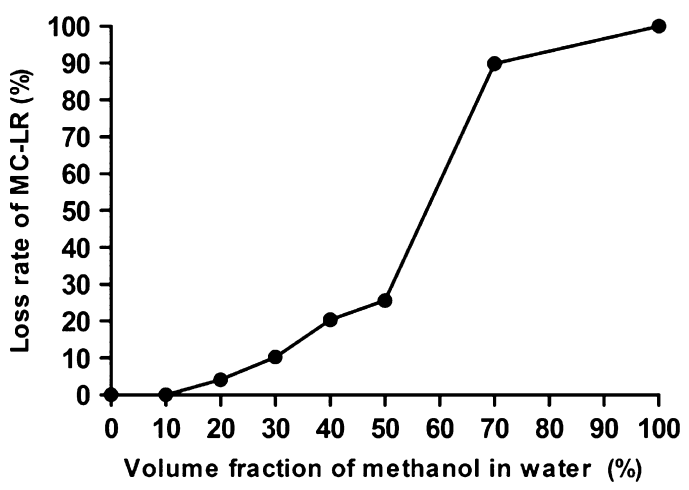

Figure 1 The loss rate of MC-LR in different volume fractions of methanol in water.

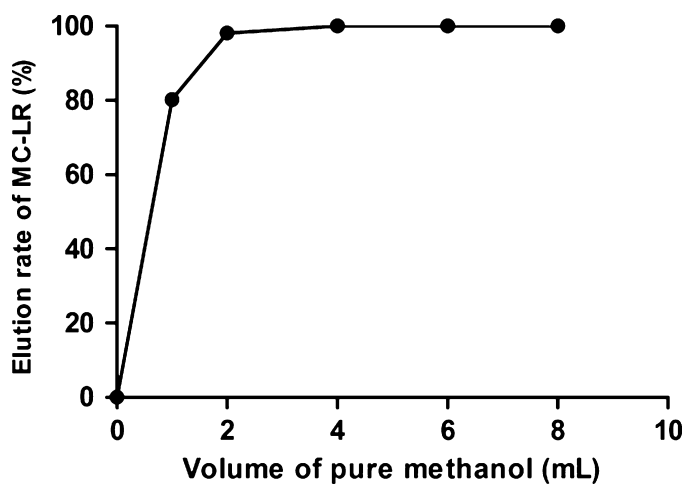

Figure 2 Curve of elution rate of MC-LR against volume of pure methanol.

provided clean and background-free mass traces for the matrix studied, demonstrating that the method had good selectivity (Fig. 3). Quantification matrix-fortified calibration curves were determined to compensate for the matrix effect and loss in sample preparation. Good linearity was obtained for MC-LR, with $r^{2}$ ranging from 0.9946 to 0.9990. The LOD and LOQ in this method were $0.0075 \mu \mathrm{g} \mathrm{g}^{-1}$ and $0.01575 \mu \mathrm{g} \mathrm{g}^{-1}$ respectively. The results are summarized in Table 3.

Satisfactory MC-LR recoveries were obtained ranging between $84.8 \pm 7.6 \%$ and $128.4 \pm 11.3 \%$. The precision was satisfactory since RSD of the mean recovery ranged from $4.2 \%$ to $10.9 \%$. The results demonstrated that the accuracy and repeatability of the method were good for quantitative purposes.

\section{Experimental results}

Microcystin-LR in the cells of M. aeruginosa was $119.67 \pm 14.01{\mu \mathrm{g} \mathrm{g}^{-1}}$ dry weight and in 
(a)

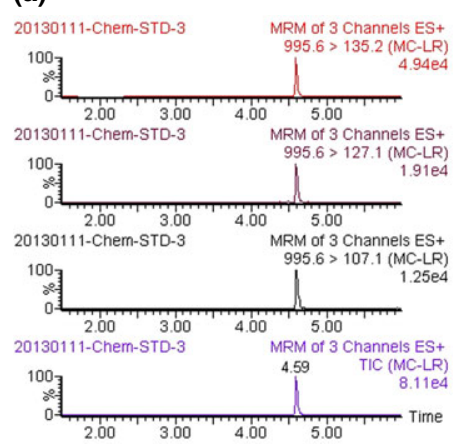

(d)

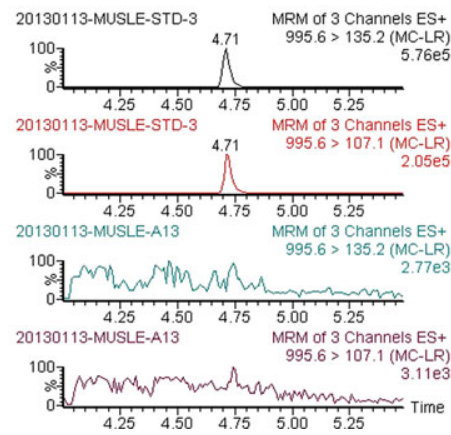

(b)

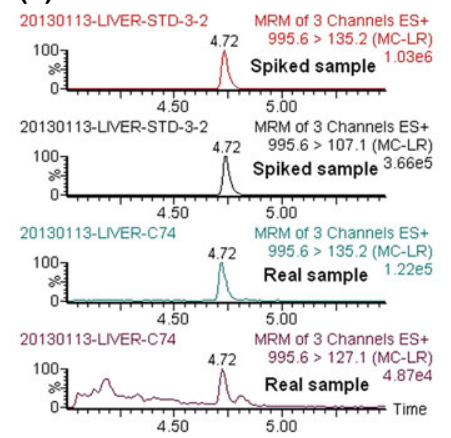

(e)

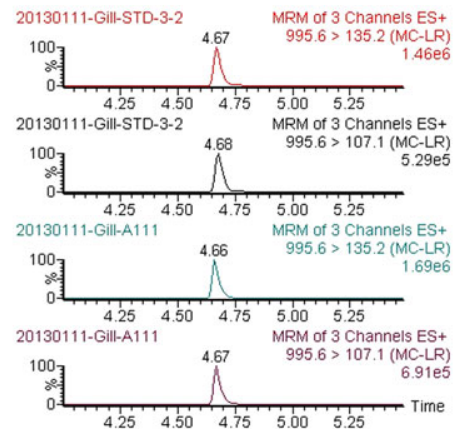

(c)

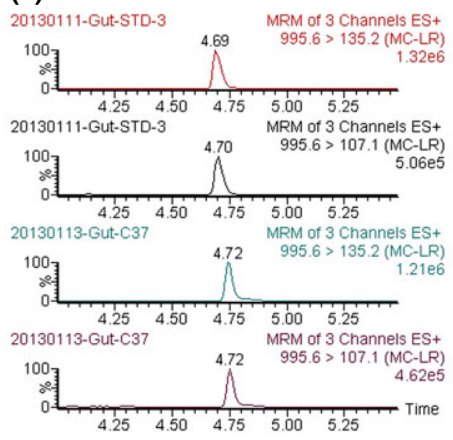

(f)

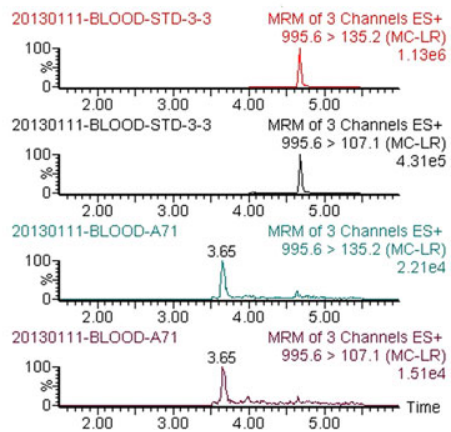

Figure 3 Chromatograms of the MC-LR in the samples. (a) Chemical standard MC-LR at $100 \mathrm{ng} \mathrm{g}^{-1}$. (b) The blank hepatopancreas sample spiked at $100 \mathrm{ng} \mathrm{g}^{-1} \mathrm{MC}-\mathrm{LR}$ and real hepatopancreas samples. (c) The blank digestive tract samples spiked at $100 \mathrm{ng} \mathrm{g}^{-1}$ MC-LR and real digestive tract samples (up to down). (d) The blank muscle sample spiked at $100 \mathrm{ng} \mathrm{g}^{-1} \mathrm{MC}$-LR and real muscle samples (up to down). (e) The blank gills sample spiked at $100 \mathrm{ng} \mathrm{g}^{-1} \mathrm{MC}-\mathrm{LR}$ and real gills samples (up to down). (f) The blank blood sample spiked at $100 \mathrm{ng} \mathrm{g}^{-1} \mathrm{MC}-\mathrm{LR}^{-}$ and real blood samples (up to down).

Table 3 The calibration curve of MC-LR and recovery tests of HPLC-MS/MS method $(n=6)$

\begin{tabular}{|c|c|c|c|c|c|}
\hline Tissue & Standard curve & $r^{2}$ & MC-LR $\left(\mu \mathrm{g} \mathrm{g}^{-1}\right)$ & Recovery (\%) & RSD (\%) \\
\hline \multirow[t]{3}{*}{ Blood } & $Y=259.83 X-2.53$ & 0.9990 & 0.075 & $91.7 \pm 5.2$ & 5.7 \\
\hline & & & 1.5 & $99.2 \pm 10.5$ & 10.5 \\
\hline & & & 3.75 & $103.7 \pm 4.3$ & 4.2 \\
\hline \multirow[t]{3}{*}{ Muscle } & $Y=262.45 X-2.71$ & 0.9975 & 0.075 & $91.5 \pm 10.5$ & 10.9 \\
\hline & & & 1.5 & $84.8 \pm 7.6$ & 9.0 \\
\hline & & & 3.75 & $111.4 \pm 6.5$ & 5.8 \\
\hline \multirow[t]{3}{*}{ Gills } & $Y=301.00 X-2.83$ & 0.9952 & 0.075 & $125.2 \pm 12.2$ & 9.7 \\
\hline & & & 1.5 & $99.7 \pm 4.7$ & 4.7 \\
\hline & & & 3.75 & $100.7 \pm 5.0$ & 5.0 \\
\hline \multirow[t]{3}{*}{ Hepatopancreas } & $Y=451.70 X-2.84$ & 0.9968 & 0.075 & $104.3 \pm 4.8$ & 4.6 \\
\hline & & & 1.5 & $88.6 \pm 8.6$ & 9.8 \\
\hline & & & 3.75 & $99.2 \pm 5.8$ & 5.8 \\
\hline \multirow[t]{3}{*}{ Digestive tract } & $Y=652.27 X-2.72$ & 0.9946 & 0.075 & $128.4 \pm 11.3$ & 8.8 \\
\hline & & & 1.5 & $96.2 \pm 6.1$ & 6.3 \\
\hline & & & 3.75 & $95.1 \pm 6.4$ & 6.8 \\
\hline
\end{tabular}

D. magna $2.72 \pm 0.09 \mu \mathrm{g} \mathrm{g}^{-1}$ dry weight respectively. The highest MC-LR peaks in the gills of prawns appeared at $8 \mathrm{~h}\left(6.08 \pm 0.59 \mu \mathrm{g} \mathrm{g}^{-1}\right.$ dry weight) in experiment $\mathrm{A}$. The digestive tracts of prawns showed remarkably high peaks at $16 \mathrm{~h}$ $\left(2.19 \pm 0.30 \mu \mathrm{g} \mathrm{g}^{-1}\right.$ dry weight), whereas the highest MC-LR content in the hepatopancreas appeared at $24 \mathrm{~h} \quad\left(0.49 \pm 0.04 \mu \mathrm{g} \mathrm{g}^{-1}\right.$ dry 
weight) in experiment C (Fig. 4). MC-LR was not detected in the muscles, and rarely appeared in blood samples in this study (Table 4). Cyanobacteria (M. aeruginosa) were observed in the gills of prawns in both experiments $\mathrm{A}$ and $\mathrm{C}$.
In all treated prawns, the average MC-LR content in the hepatopancreas rapidly increased during the experimental period (Figs 4 and 5). The highest MC-LR levels were recorded in the gills and digestive tracts of the prawns (Fig. 6). The
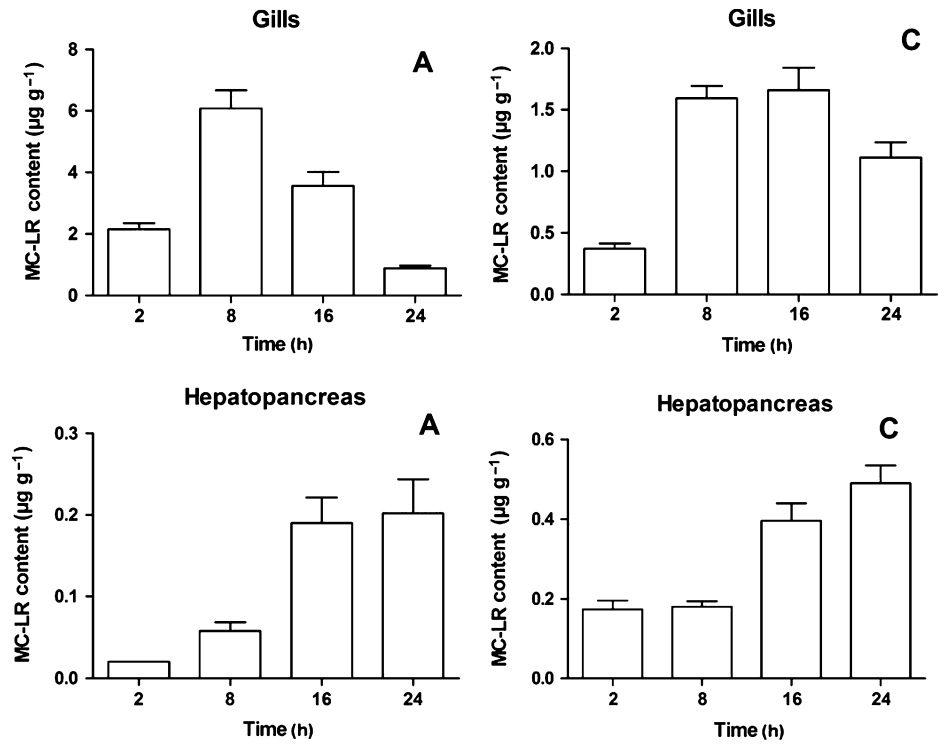

Figure 4 MC-LR contents in gills, hepatopancreas and digestive tract of prawns from experiments $A$ and C. Bars represent means \pm SD of four replicates.
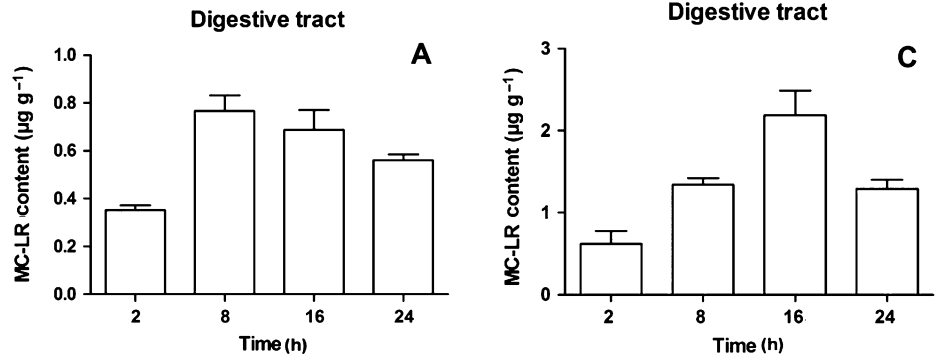

Table 4 MC-LR content accumulated in different prawn tissues within $24 \mathrm{~h}$ in the three experiments $(n=10)^{*}$

\begin{tabular}{|c|c|c|c|c|c|c|}
\hline \multirow{2}{*}{\multicolumn{2}{|c|}{ Experiment/Time (h) }} & \multicolumn{5}{|c|}{ MC-LR content ( $\mu \mathbf{g ~ g}^{-1}$ dry weight) } \\
\hline & & Blood & Muscle & Gills & Hepatopancreas & Digestive tract \\
\hline \multirow[t]{4}{*}{ A } & 2 & ND & ND & $2.16 \pm 0.19^{a}$ & $0.02 \pm 0.00^{a}$ & $0.35 \pm 0.02^{a}$ \\
\hline & 8 & $0.15 \pm 0.004$ & ND & $6.08 \pm 0.59^{b}$ & $0.06 \pm 0.01^{a}$ & $0.77 \pm 0.07^{\mathrm{b}}$ \\
\hline & 16 & ND & ND & $3.57 \pm 0.44^{a}$ & $0.19 \pm 0.03^{b}$ & $0.69 \pm 0.08^{b}$ \\
\hline & 24 & ND & ND & $0.89 \pm 0.08^{c}$ & $0.20 \pm 0.04^{b}$ & $0.56 \pm 0.02^{\mathrm{ab}}$ \\
\hline \multirow[t]{3}{*}{$B$} & 8 & ND & ND & $0.05 \pm 0.005$ & $0.04 \pm 0.02^{a}$ & $0.05 \pm 0.01^{a}$ \\
\hline & 16 & ND & ND & ND & $0.05 \pm 0.01^{a}$ & $0.14 \pm 0.01^{\mathrm{b}}$ \\
\hline & 24 & $0.02 \pm 0.005$ & ND & ND & $0.10 \pm 0.02^{b}$ & $0.40 \pm 0.04^{c}$ \\
\hline \multirow[t]{4}{*}{ C } & 2 & ND & ND & $0.37 \pm 0.04^{\mathrm{a}}$ & $0.17 \pm 0.02^{\mathrm{a}}$ & $0.62 \pm 0.16^{a}$ \\
\hline & 8 & ND & ND & $1.59 \pm 0.09^{b}$ & $0.18 \pm 0.01^{a}$ & $1.34 \pm 0.08^{b}$ \\
\hline & 16 & ND & ND & $1.66 \pm 0.18^{\mathrm{b}}$ & $0.40 \pm 0.04^{b}$ & $2.19 \pm 0.30^{c}$ \\
\hline & 24 & $0.03 \pm 0.005$ & ND & $1.11 \pm 0.12^{\mathrm{b}}$ & $0.49 \pm 0.04^{b}$ & $1.29 \pm 0.11^{\mathrm{b}}$ \\
\hline
\end{tabular}

*Values represent means \pm SD of four replicates.

Means of each experiment in the same column with different superscript letters are significantly different $(P<0.05)$. 

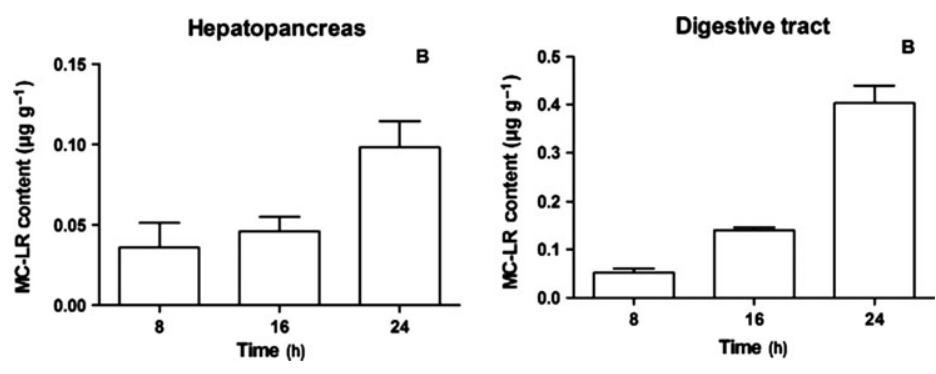

Figure 5 MC-LR concentrations in hepatopancreas and digestive tract of prawns from experiment $\mathrm{B}$. Bars represent means \pm SD of four replicates.

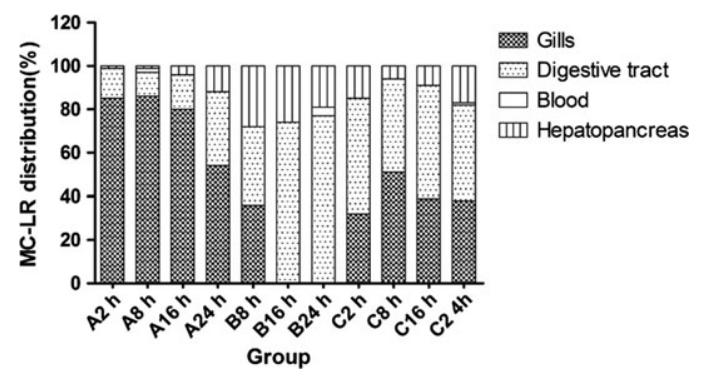

Figure 6 Distribution of MC-LR (\%) in the prawn tissues at different times in experiments A, B and C.

average MC-LR content of experiment $\mathrm{A}$ in the gills and digestive tracts increased initially (around $8 \mathrm{~h}$ ), then decreased until the end of the test (Fig. 4). However, the average MC-LR content in the gills and digestive tracts in experiment $\mathrm{C}$ increased initially then decreased after $16 \mathrm{~h}$. Prawns accumulated a maximum of $6.08 \pm 0.59$ $\mu \mathrm{g} \mathrm{g}^{-1}$ dry weight in the gills in experiment A.

\section{Discussion}

Aquatic organisms are generally considered more tolerant of cyanobacteria toxins than mammals as a result of their co-evolutionary history, which can reduce the likelihood for catastrophic losses of the cultured species but increase the potential for damaging human exposure to these toxins (Smith et al. 2008). Bioaccumulation of MCs in crustaceans has been reported in several publications. Vasconcelos, Oliveira and Teles (2001) detected a concentration of $2.9 \mu \mathrm{g} \mathrm{g}^{-1}$ dry weight in crayfish Procambarus clarkii under laboratory conditions. The seasonal changes of mixed hepatotoxins (MCLR, MC-LA, MC-RR, MC-YR and NODLN) in the marine prawn Penaeus monodon was measured through the enzyme linked immunosorbent assays method and the total concentration of hepatotoxins in P. monodon hepatopancreas varied between 0.0064 and $0.0816 \mu \mathrm{g} \mathrm{g}^{-1}$ DW (Kankaanpää, Holliday, Schroder, Goddard, von Fister \&
Carmichael 2005). Zhang et al. (2009) studied seasonal variations of MC-LR contents in shrimp (Macrobrachium nipponensis) from Lake Taihu through LC-ESI-MS, and found that the MC-LR concentrations ranged from $0.031 \pm 0.004$ to $0.605 \pm 0.179 \quad \mathrm{Mg} \mathrm{g}^{-1} \quad \mathrm{DW}$ with averaging $0.244 \pm 0.220 \mu \mathrm{g} \mathrm{g}^{-1} \mathrm{DW}$. In our study, the toxin concentration shown by freshwater prawns is consistent with the reported cases in the hepatopancreas (maximum $0.49 \mu \mathrm{g} \mathrm{g}^{-1} \mathrm{DW}$ ). Nevertheless, Zimba, Camus, Allen and Burkholder (2006) reported a case of co-occurrence of white shrimp, Litopenaeus vannamei, mortalities and microcystin toxin in ponds, where water samples from the affected pond contained high levels of MC-LR $\left(45 \mu \mathrm{g} \mathrm{g}^{-1}\right)$, and free MC-LR concentrations in dead shrimp hepatopancreas determined by HPLC were $55 \mu \mathrm{g} \mathrm{g}^{-1}$ total shrimp weight. However, we did not determine the total MC load in prawn. The common results from the above references demonstrated that crustacean muscle was not the primary organ for hepatotoxin bioaccumulation.

In this study, MC-LR was detected in the gills, digestive tracts and hepatopancreas of the prawns after $2 \mathrm{~h}$ of exposure. The prawns accumulated MC-LR both directly from $M$. aeruginosa (Experiment A) and indirectly through D. magna (Experiment B) which was pre-exposed to M. aeruginosa. To our best knowledge, this might be the first evidence that freshwater prawns accumulate MC-LR in very short time, as well as the direct transfer of MC-LR from zooplankton to prawns and the subsequent accumulation of toxin in the hepatopancreas and digestive tract.

According to our results, MC appears to be absorbed through the digestive tract of prawns at a higher rate when the toxin is administered through a vector, D. magna, rather than through toxic cyanobacteria directly. In experiment $C$, as prawns and D. magna were exposed to M. aeruginosa together, D. magna ingested toxic cyanobacteria cells and prawns appeared to consume these 
toxic D. magna, based on the decrease in MC-LR content in prawn gills and the increase in MC-LR concentrations in hepatopancreas and digestive tracts. Thus, other aquaculture species may also be exposed to MC through the ingestion of cyanobacteria (Ortiz-Rodríguez \& Wiegand 2010), consumption of contaminated food items (e.g. prey or detritus) (Deblois et al. 2011) and absorption of dissolved MC from the water column (e.g. after leakage from cells or cell lysis) (Vasconcelos et al. 2001).

Microcystins are usually taken up from intestine and transferred to liver tissue (Fischer \& Dietrich 2000). In this study, we found that prawns ingested M. aeruginosa cells directly. We also observed that algal cells adhered to the gills of prawns. There was no evidence that the gills absorbed microcystin through algae lysis, nevertheless, the possibility of this pathway should not be disregarded.

The UPLC-MS/MS analysis method used herein shortened analysis time significantly, with peak time for MC-LR appearing at 4.5-4.8 $\mathrm{min}$. Comparatively, it took $18.51 \mathrm{~min}$ to analyse MC-LR content in Litopenaeus vannamei samples using HPLC/MS method (Zimba et al. 2006), while similar retention time $(\sim 21 \mathrm{~min})$ was recorded for two tilapia species Oreochromis niloticus and Tilapia rendalli using HPLC method (Deblois et al. 2008).

The 24-h test was not sufficient to promote accumulation of MC-LR in the muscle, which is the edible part of the prawn for human consumption. Future studies should take this into consideration. The provisional TDI suggested by WHO is $0.04 \mu \mathrm{g} \mathrm{kg}^{-1}$ of body weight or $2.4 \mu \mathrm{g}$ for an adult human weighing $60 \mathrm{~kg}$ (Kuiper-Goodman, Falconer \& Fitzerald 1999). Assuming an adult human ingests $100 \mathrm{~g}$ of whole prawns per day from our experiment $\mathrm{A}$ and $\mathrm{C}$, then daily uptake of MC-LR would range from 116 to $706 \mu \mathrm{g}$, much higher than TDI value proposed by WHO, which was unsafe for human consumption. Therefore, the risk of consuming prawns from aquaculture ponds and lakes during toxic cyanobacteria blooms cannot be overlooked, and regular monitoring of MC levels in prawns should be conducted to protect health of consumers. We recommend that future studies evaluate the total MC tissue load and the potentially harmful effects of MC on human health by multiple exposure routes through aquatic food.

\section{Acknowledgments}

The authors would thank Li Zhi, Lin Jing and Yue Yaling for technical support. This research is funded by the National Natural Science Foundation of China (contract no. 31101914), the Aquaculture \& Fisheries Collaborative Research Support Program (AquaFish CRSP) through Oregon State University and Michigan University under USAID Grant (no. EPP-A-00-06-00012-00), and the 7th EU Framework Program project "Sustaining Ethical Aquaculture Trade" (contract no. 222889) and the Analysis and Testing Foundation of Zhejiang, China (no. 2011C37038) and the Shanghai Universities First-class Disciplines Project of Fisheries.

\section{References}

Andersen R.J., Luu H.A., Chen D.Z.X., Holmes C.F.B., Kent M.L., Le Blanc M., Taylor F.J.R. \& Williams D.E. (1993) Chemical and biological evidence links microcystins to salmon 'netpen liver disease'. Toxicon $\mathbf{3 1}$, 1315-1323.

Beaver J.R., Manis E.E., Loftin K.A., Graham J.L., Pollard A.I. \& Mitchell R.M. (2014) Land use patterns, ecoregion, and microcystin relationships in U.S. lakes and reservoirs: a preliminary evaluation. Harmful Algae 36, $57-62$.

Cazenave J., Wunderlin D.A., Bistoni M., Améd L.A., Krause M.V., Pflugmacher E. \& Wiegand S.C. (2005) Uptake, tissue distribution and accumulation of microcystin-RR in Corydoras paleatus, Jenynsia multidentata and Odontesthes bonariensis. A field and laboratory study. Aquatic Toxicology 75, 178-190.

Chen J. \& Xie P. (2005) Tissue distributions and seasonal dynamics of the hepatotoxic microcystins-LR and -RR in two freshwater shrimps, Palaemon modestus and Macrobrachium nipponensis, from a large shallow, eutrophic lake of the subtropical China. Toxicon 45, 615625.

Chen J., Xie P., Zhang D., Ke Z. \& Yang H. (2006) In situ studies on the bioaccumulation of microcystins in the phytoplanktivorous silver carp (Hypophthalmichthys molitrix) stocked in Lake Taihu with dense toxic Microcystis blooms. Aquaculture 261, 1026-1038.

Chen J., Zhang D., Xie P., Wang Q. \& Ma Z. (2009) Simultaneous determination of microcystin contaminations in various vertebrates (fish, turtle, duck and water bird) from a large eutrophic Chinese lake, Lake Taihu, with toxic Microcystis blooms. Science of the Total Environment 407, 3317-3322.

Chen J., Xie P., Li L. \& Xu J. (2009) First identification of the hepatotoxic microcystins in the serum of a chronically exposed human population together with indica- 
tion of hepatocellular damage. Toxicological Sciences 108, 81-89.

Chorus I. \& Bartram J. (1999) Toxic Cyanobacteria in Water-a Guide to Public Health Consequences, Monitoring and Management. E \& FN Spon, London, 416 pp. Published on behalf of World Health Organization.

Codd G.A., Lindsay J., Young F.M., Morrison L.F. \& Metcalf J.S. (2005) From mass mortalities to management measures. In: Harmful Cyanobacteria. Aquatic Ecology Series (ed. by J. Huisman, H.C.P. Matthijs \& P.M. Visser), pp. 1-23. Springer-Verlag New York Inc., New York, USA.

Codd G.A., Morrison L.F. \& Metcalf J.S. (2005) Cyanobacterial toxins: risk management for health protection. Toxicology and Applied Pharmacology 203, 264-272.

Deblois C.P., Aranda-Rodriguez R., Giani A. \& Bird D.F. (2008) Microcystin accumulationin liver and muscle of tilapia in two large Brazilian hydroelectric reservoirs. Toxicon 51, 435-448.

Deblois C.P., Gianib A. \& Bird D.F. (2011) Experimental model of microcystin accumulation in the liver of Oreochromis niloticus exposed subchronically to a toxic bloom of Microcystis sp. Aquatic Toxicology 103, 63-70.

Dietrich D.R. \& Hoeger S.J. (2005) Guidance values for microcystin in water and cyanobacterial supplement products (blue-green algae supplements): a reasonable or misguided approach? Toxicology and Applied Pharmacology 203, 273-289.

Engström-Öst J., Lehtiniemi M., Green S., Kozlowsky-Suzuki B. \& Viitasalo M. (2002) Does cyanobacterial toxin accumulate in mysid shrimps and fish via copepods? Journal of Experimental Marine Biology and Ecology 276, 95-107.

Fischer W.J. \& Dietrich D.R. (2000) Pathological and biochemical characterization of microcystin-induced hepatopancreas and kidney damage in carp (Cyprinus carpio). Toxicology and Applied Pharmacology 1, 73-81.

Ibelings B.W. \& Chorus I. (2007) Accumulation of cyanobacterial toxins in freshwater "seafood" and its consequences for public health: a review. Environmental Pollution 150, 177-192.

Ibelings B.W., Bruning K., de Jonge J., Wolfstein K., Pires L.M.D., Postma J. \& Burger T. (2005) Distribution of microcystins in a lake foodweb: no evidence for biomagnification. Microbial Ecology 49, 487-500.

Kankaanpää H.T., Holliday J., Schroder H., Goddard T.J., von Fister R. \& Carmichael W.W. (2005) Cyanobacteria and prawn farming in northern New South Wales, Australia-a case study on cyanobacteria diversity and hepatotoxin bioaccumulation. Toxicology and Applied Pharmacology 203, 243-256.

Karjalainen M., Reinikainen M., Spoof L., Meriluoto J.A.O. \& Sivonen K. (2005) Trophic transfer of cyanobacterial toxins from zooplankton to planktivores: consequences for pike larvae and mysid shrimps. Environmental Toxicology 20, 354-362.
Kuiper-Goodman T., Falconer I. \& Fitzerald J. (1999) Human health aspects. In: Toxic Cyanobacteria in Water: A Guide to their Public Health Consequences, Monitoring and Management (ed. by I. Chorus \& J. Bartman), pp. 126-134. Taylor \& Francis, London, UK.

Lance E., Brient L., Bormans M. \& Gérard C. (2006) Interactions between cyanobacteria and Gastropods I. Ingestion of toxic Planktothrix agardhii by Lymnaea stagnalis and the kinetics of microcystin bioaccumulation and detoxification. Aquatic Toxicology 79, 140-148.

Liu L.P., Li K., Chen T.Y., Dai X.L., Jiang M. \& Diana J.S. (2011) Effects of Microcystis aeruginosa on the life history of water flea Daphnia magna. Chinese Journal of Oceanology and Limnology 29, 892-897.

Liu W., Qiao Q., Chen Y., Wu K. \& Zhang X. (2014) Microcystin-LR exposure to adult zebrafish (Danio rerio) leads to growth inhibition and immune dysfunction in F1 offspring, a parentaltransmission effect of toxicity. Aquatic Toxicology 155, 360-367.

Mohamed Z.A., Carmichael W.W. \& Hussein A.A. (2003) Estimationof microcystins in the freshwater fish Oreochromis niloticus in an Egyptian fish farm containing a Microcystis bloom. Environmental Toxicology 18, 137-141.

Ortiz-Rodríguez R. \& Wiegand C. (2010) Age related acute effects of microcystin-LR on Daphnia magna biotransformation and oxidative stress. Toxicon 56, 13421349.

Ozawa K., Yokoyama A., Ishikawa K., Kumagai M., Watanabe M.F. \& Park H.D. (2003) Accumulation and depurationof microcystin produced by the cyanobacterium Microcystisin a freshwater snail. Limnology 4, 131-138.

Smith J.L. \& Haney J.F. (2006) Foodweb transfer, accumulation, and depuration of microcystins, a cyanobacterial toxin, in pumpkinseed sunfish (Lepomis gibbosus). Toxicon 48, 580-589.

Smith J.L., Boyer G.L. \& Zimba P.V. (2008) A review of cyanobacterial odorous and bioactive metabolites: impacts and management alternatives in aquaculture. Aquaculture 280, 5-20.

Vareli K., Zarali E., Zacharioudakis G.S.A., Vagenas G., Varelis V., Pilidis G., Briasoulis E. \& Sainis I. (2012) Microcystin producing cyanobacterial communities in Amvrakikos Gulf (Mediterranean Sea, NW Greece) and toxin accumulation in mussels (Mytilus galloprovincialis). Harmful Algae 15, 109-118.

Vasconcelos V.M., Oliveira S. \& Teles F.O. (2001) Impact of a toxicand a non-toxic strain of Microcystis aeruginosa on the crayfish Procambarus clarkia. Toxicon 39 , 1461-1470.

Wilson A.E., Gossiaux D.C., Hook T.O., Berry J.P., Landrum P.F., Dyble J. \& Guildford S.J. (2008) Evaluation of the human health threat associated with the hepatotoxin microcystin in the muscle and liver tissues of yellow perch (Perca flavescens). Canadian Journal of Fisheries and Aquatic Sciences 65, 1487-1497. 
Xie L., Xie P., Guo L.G., Li L., Miyabara Y. \& Park H. (2005) Organ distribution and bioaccumulation of microcystins in freshwater fishes with different trophic levels from the eutrophic Lake Chaohu, China. Environmental Toxicology 20, 292-300.

Xie L., Yokoyama A., Nakamura K. \& Park H. (2007) Accumulation of microcystins in various organs of the freshwater snail Sinotaia histrica and three fishes in a temperate lake, the eutrophic LakeSuwa, Japan. Toxicon 49, 646-652.

Zhang D., Xie P., Chen J., Dai M., Qiu T., Liu Y. \& Liang G. (2009) Determination of microcystin-LR and its metabolites in snail (Bellamya aeruginosa), shrimp
(Macrobrachium nipponensis) and silver carp (Hypophthalmichthys molitrix) from Lake Taihu, China. Chemosphere 76, 974-981.

Ziková A., Lorenz C., Lutz I., Pflugmacher S. \& Kloas W. (2013) Physiological responses of Хenopus laevis tadpoles exposed to cyanobacterial biomass containing microcystin-LR. Aquatic Toxicology 128-129, 25-33.

Zimba P.V., Camus A., Allen E.H. \& Burkholder J.M. (2006) Co-occurrence of white shrimp, Litopenaeus vannamei, mortalities and microcystin toxin in a southeastern USA shrimp facility. Aquaculture 261, 10481055. 